\title{
A Case of Graves' Disease Associated with Painful Thyroiditis
}

\author{
SHIGENORI NAKAMURA, YUKIE SAIO, AND MASATOSHI ISHIMORI \\ Department of Internal Medicine, Gifu Red Cross Hospital, Gifu 502, Japan
}

\begin{abstract}
We report on a 61-year-old woman with untreated Graves' disease associated with painful thyroiditis. On examination, the left lobe of the thyroid gland was firm and tender but the right lobe was not. A diagnosis of Graves' disease was made based on the results of thyroid function tests including the percentage of thyroidal radioactive iodine uptake (RAIU) and the presence of thyroidstimulating antibodies (TSAb). However, ultrasonogram results and inflammatory findings (C-reactive protein concentration and erythrocyte sedimentation rate) also indicated the presence of inflammation in the thyroid gland. She was first treated with aspirin, and later with prednisolone. Her clinical course was similar to that in cases of subacute thyroiditis, but neither her HLA type nor aspiration cytology findings indicated the type of thyroiditis. With the resolution of the thyroiditis, her serum levels of thyroid hormone and TSAb decreased, although RAIU increased. Finally, she became euthyroid without antithyroid drug treatment. The serum levels of antithyroid antibodies, TSH-binding inhibitor immunoglobulins (TBII) and TSAb increased transiently and then decreased during the course of the illness, indicating that the mechanism(s) of the production and/or degradation of TBII and TSAb is similar to that for antithyroid antibodies in the present case. The present findings also indicate that remission may occur in some patients with Graves' disease after painful thyroiditis is resolved.
\end{abstract}

Key words: Graves' disease, Thyroiditis, Pain, Remission, TSH-receptor antibodies

(Endocrine Journal 44: 611-616, 1997)

PAIN in the thyroid gland or painful thyroiditis occurs rarely in patients with untreated [1-3] or treated Graves' disease [2, 4,5]. Such pain is reported to be caused by subacute thyroiditis [1, $3]$, acute exacerbation of underlying chronic thyroiditis [4, 5], or unknown factors [2]. Upon the resolution of such pain, many patients develop hypothyroidism $[2,4,5]$, while a few patients become euthyroid [1] or remain hyperthyroid [3]. Nevertheless, the mechanism(s) underlying the changes in the results of thyroid function tests including the percentage of thyroidal radioactive iodine uptake (RAIU) in such cases is not fully

Received: January 30, 1997

Accepted: April 21, 1997

Correspondence to: Dr. Shigenori NAKAMURA, Department of Internal Medicine, Gifu Red Cross Hospital, 3-36 Iwakura, Gifu 502, Japan understood. In addition, it remains unknown which patients are likely to become hypothyroid or euthyroid, or remain hyperthyroid after the resolution of such pain.

Here we report the case of a patient with Graves' disease whose thyroid function became normal after an attack of painful thyroiditis and investigate the changes in serum levels of thyroid-related antibodies including thyroid-stimulating antibodies (TSAb) and in the patient's RAIU.

\section{Methods}

Serum samples were stored at $-20{ }^{\circ} \mathrm{C}$ until assayed. Serum levels of T3, T4, and TSH were measured by radioimmunoassay (RIA) or immunoradiometric assay (IRMA) with commercially available kits (SPAC T3 and SPAC 
T4 RIA kits, Daiichi Radioisotope, Tokyo and TSHRIA BEAD II kit, Dainabott, Tokyo). The normal ranges of serum T3, T4 and TSH levels were 1.4$2.3 \mathrm{nmol} / l, 60-151 \mathrm{nmol} / l$ and $0.41-4.10 \mathrm{mU} / l$, respectively. Serum levels of anti-thyroglobulin antibodies $(\mathrm{TgAb})$ and anti-thyroid peroxidase antibodies (TPOAb) were also determined by RIA (TgAb-Cosmic and TPOAb-Cosmic, Cosmic Corporation, Tokyo) (normal range: $\leqq 0.3 \mathrm{U} / \mathrm{ml}$ for both assays). Serum levels of thyroglobulin ( $\mathrm{Tg}$ ) were also measured by IRMA (ThyroglobulinIRMA Pasteur, Daiichi Radioisotope, Tokyo). The normal range was less than $35 \mu \mathrm{g} / \mathrm{l}$. The 24-h RAIU was determined by a standard procedure (normal range: $10-40 \%$ ). Serum levels of TSH-binding inhibitor immunoglobulins (TBII) were measured in terms of the extent of inhibition of ${ }^{125}$ I-TSH binding to its receptor (Kodak TRAb kit, Tokyo) (normal range: $<15 \%$ ). Serum levels of both TSAb and thyroid-stimulation blocking antibodies (TSBAb) were measured by using rat thyroid cells (FRTL-5) instead of porcine thyroid cells [6]. Bovine (b) TSH (Sigma Chemical Co., St. Louis, MO) was used as the standard for thyroid stimulation, and TSAb activity was expressed as bTSH equivalent (normal range: $\leqq 0.3 \mathrm{mU} / l \mathrm{bTSH}$ equivalent). TSBAb activity was expressed as the percent inhibition of bTSH $(100 \mathrm{mU} / \mathrm{l})$-stimulated cAMP increase (normal range: <20\%). Serum levels of T3, T4, TSH, Tg and TBII were determined at each visit for determination of the patient's thyroidal state, and serum levels of TgAb, TPOAb, $T S A b$ and TSBAb were measured in one assay run.

\section{Case Report}

A 61-year-old woman was referred to our hospital on January 17, 1994. She had been in good health until early January 1994, when she noticed a cough and nasal discharge. She developed pain and tenderness in the left side of the neck on January 7,1994 . She consulted a physician on January 10,1994. At that time, the left lobe of the thyroid gland was enlarged and tender. Serum levels of free T3, free T4 and TSH were $16.9 \mathrm{pmol} / \mathrm{l}$ (normal range: $4.0-8.3$ ), $73 \mathrm{pmol} / l$ (normal range: 10-24) and less than $0.10 \mathrm{mU} / \mathrm{ml}$ (normal range: $0.6-4.9)$, respectively. The C-reactive protein (CRP) concentration was $3.75 \mathrm{mg} / \mathrm{d} l$ and the erythrocyte sedimentation rate (ESR) was $109 \mathrm{~mm} / \mathrm{h}$. Her white blood cell (WBC) count was $6.6 \times 10^{9} / l$. Cefdinal (an antibiotic) was administered, but her symptoms did not improve. She also noticed excessive sweating, palpitations, and body weight loss (2-3 kg/month), but was not aware of fever or finger tremor. A family history of thyroid disease was not elicited. Her HLA type was A11, B54(22), B62(15), Cw1, Cw4, DR4, DR8, DQ1 and DQ 3.

On physical examination, her height was $152 \mathrm{~cm}$ and weight was $42 \mathrm{~kg}$. Her temperature was 36.2 ${ }^{\circ} \mathrm{C}$, pulse rate 108 beats per $\mathrm{min}$, and blood pressure $138 / 82 \mathrm{mmHg}$. Her skin was moist, and there was no exophthalmos. Her thyroid gland was moderately enlarged. The left lobe of the thyroid gland was firm and tender, while the right lobe was rubbery and not tender. There was no finger tremor. Reflexes were hyperactive. The remainder of the examination revealed no contributory findings.

Serum levels of T3, T4 and TSH were $5.3 \mathrm{nmol} / l$, $438 \mathrm{nmol} / l$ and less than $0.10 \mathrm{mU} / l$, respectively. $\mathrm{TgAb}$ and TPOAb were detected at low levels in her serum. Her serum Tg concentration was high $(629 \mu \mathrm{g} / l)$. Her serum was positive for TBII and TSAb but negative for TSBAb. The CRP concentration was $5.51 \mathrm{mg} / \mathrm{d} l$ and the ESR was $119 \mathrm{~mm} / \mathrm{h}$. The WBC count was $4.0 \times 10^{9} / l$. Ultrasonography of the thyroid gland on January 17 showed irregular, hypoechoic lesions at the lateral side of both lobes (Fig. 1). In addition, the presence of a small cyst in the left lobe of the thyroid gland was revealed. Treatment with aspirin (1.0 g/day) was started on January 17. RAIU on January 25 was $21.4 \%$ and a scintigram of the thyroid gland showed decreased ${ }^{123}$ I uptake in the upper pole of the left lobe and at the lateral side of the right lobe (Fig. 2a). Based on these findings, she was diagnosed as having Graves' disease associated with thyroiditis. She developed a fever $\left(38^{\circ} \mathrm{C}\right)$ and noticed right neck pain on January 25 . The right lobe of the thyroid gland became firm and tender. Fine needle aspiration biopsy of the right lobe of the thyroid gland on January 27 revealed the presence of many lymphocytes, histiocytes, and neutrophils without any multinucleated giant cells. Treatment with aspirin was changed to that with prednisolone (30 $\mathrm{mg} /$ day) and bisoprolol fumarate ( $5 \mathrm{mg} /$ day) (a beta-blocker) on January 28 . In early February the thyroid gland was not tender and had decreased 


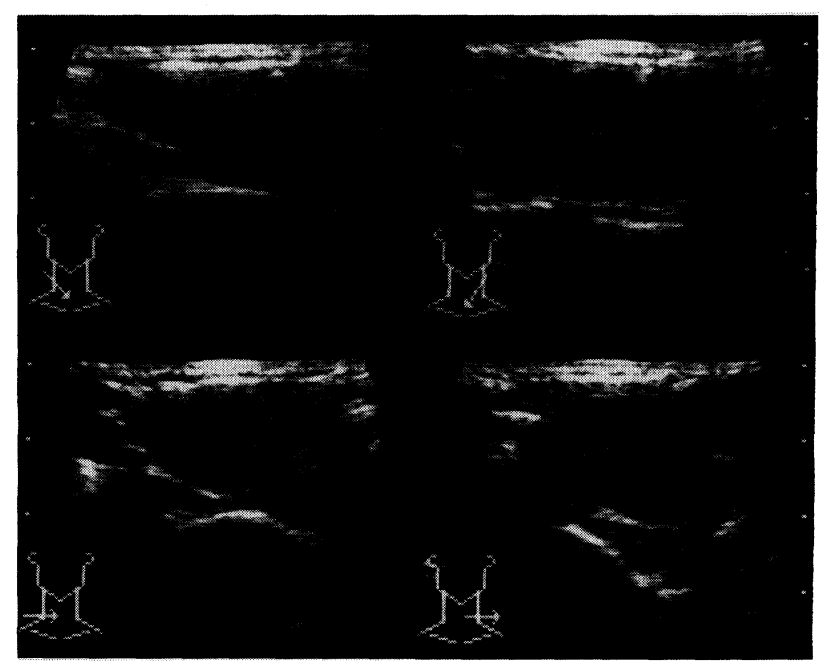

Fig. 1. Ultrasonograms obtained on January 17, 1994.

in size, but she noticed finger tremor. The RAIU test and scintigraphy were repeated on February 8. The second RAIU (25.6\%) was almost the same as the first one (21.4\%). The second scintigram, however, showed no defect in the thyroid gland (Fig.2b). Ultrasonography on February 10 showed that the hypoechoic lesion had disappeared. The dose of prednisolone was gradually decreased, and the prednisolone therapy was finally terminated on April 8, 1994. Finger tremor was not observed in May 1994. The third RAIU on May 23 was increased to $42.8 \%$. The third scintigram (Fig. 2c) was almost the same as the second one. The thyroid gland became slightly palpable in June 1994. Treatment with bisoprolol was terminated on September 8, 1994.

The changes in the CRP concentration, ESR and thyroid function are shown in Table 1. Assay results for CRP changed from positive to negative within two months after the initial examination at our hospital. The ESR also became normal in March. The total serum thyroid hormone levels gradually decreased and became normal (T3 in June 1994 and T4 in August 1994). The serum TSH level was below the detectable level up to September 1994 and then increased to the normal range. The serum $\mathrm{Tg}$ level decreased and became normal in May 1994. Serum levels of TBII, TSAb, $\mathrm{TgAb}$ and TPOAb increased transiently and then decreased. Finally activities of TBII, TSAb and TPOAb were no longer detected in her serum.

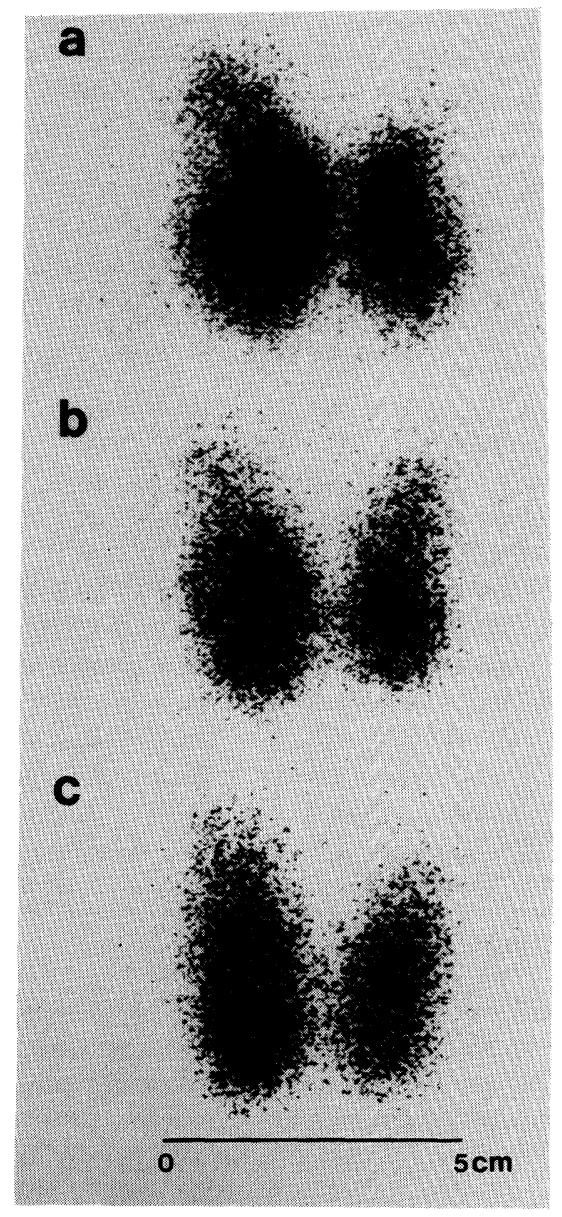

Fig. 2. Thyroid scintigrams with ${ }^{123}$ I (a: January 25, 1994, b: February 8, 1994, c: May 23, 1994)

\section{Discussion}

When the patient was first examined at our hospital in January 1994, her serum levels of thyroid hormones were high and the serum TSH level was suppressed. At that time, serum TSAb activity was detected and RAIU was normal, indicating that the patient had Graves' disease although she had a painful, tender thyroid gland. Ultrasonogram and ${ }^{123}$ I scintigram results, and inflammatory findings including the CRP concentration and ESR indicated the presence of inflammatory thyroiditis at the same time. Her clinical course was similar to that in cases of subacute thyroiditis. However, we cannot conclude that she had concomitant subacute thyroiditis since 
Table 1. Changes in thyroid function and inflammatory findings

\begin{tabular}{|c|c|c|c|c|c|c|c|c|c|c|}
\hline & $\begin{array}{c}\mathrm{T} 3 \\
(\mathrm{nmol} / l)(\mathrm{n}\end{array}$ & $\begin{array}{c}\mathrm{T} 4 \\
\mathrm{nmol} / l)\end{array}$ & $\begin{array}{c}\mathrm{TSH} \\
(\mathrm{mU} / \mathrm{l})\end{array}$ & $\begin{array}{l}\text { TBII } \\
(\%)\end{array}$ & $\begin{array}{l}\text { TSAb\# } \\
(\mathrm{mU} / l)\end{array}$ & $\begin{array}{c}\mathrm{Tg} \\
(\mu \mathrm{g} / l)\end{array}$ & $\begin{array}{c}\mathrm{CRP} \\
(\mathrm{mg} / \mathrm{d} l)\end{array}$ & $\begin{array}{c}\text { ESR } \\
(\mathrm{mm} / \mathrm{h})\end{array}$ & $\begin{array}{c}\mathrm{TgAb} \\
(\mathrm{U} / \mathrm{ml})\end{array}$ & $\begin{array}{l}\text { TPOAb } \\
(\mathrm{U} / \mathrm{m} l)\end{array}$ \\
\hline $94-01-10$ & & & $<0.1$ & & & & 3.75 & 109 & & \\
\hline 01-17 & 5.3 & 438 & $<0.1$ & 21.6 & 19.8 & 629 & 5.51 & 119 & 0.5 & 0.4 \\
\hline $01-25$ & & & RAIU & (24-h) 21 & $.4 \%$ & & & & & \\
\hline $01-27$ & 3.7 & 333 & $<0.1$ & & 25.2 & & 8.94 & 140 & 0.8 & 0.7 \\
\hline $02-04$ & & & & & & & $<0.28$ & 46 & & \\
\hline $02-08$ & & & RAIU & $(24-h) 25$ & $.6 \%$ & & & & & \\
\hline $02-10$ & 3.0 & 212 & $<0.1$ & 25.6 & 10.8 & & 1.94 & 41 & 0.8 & 0.6 \\
\hline $02-16$ & & & & & & & 1.14 & 35 & & \\
\hline $02-25$ & 3.4 & 214 & $<0.1$ & 30.2 & & 210 & 0.79 & 43 & & \\
\hline $03-11$ & 2.7 & 178 & $<0.1$ & & 11.0 & & $<0.25$ & 25 & 3.2 & 1.3 \\
\hline $04-07$ & 3.0 & 202 & $<0.1$ & 4.0 & 4.8 & 88 & $<0.25$ & 15 & 2.2 & 1.1 \\
\hline $05-12$ & 2.7 & 188 & $<0.1$ & -9.6 & 1.8 & 33 & $<0.26$ & 20 & 3.2 & 0.7 \\
\hline $05-23$ & & & RAIU & $(24-h) 42$ & $.8 \%$ & & & & & \\
\hline $06-16$ & 2.3 & 183 & $<0.1$ & -2.9 & 0.9 & 17 & $<0.26$ & 17 & 3.5 & 0.5 \\
\hline $08-11$ & 1.6 & 126 & $<0.1$ & -10.4 & 0.5 & 27 & 0.44 & 27 & 3.9 & $<0.3$ \\
\hline $09-08$ & 1.7 & 115 & $<0.1$ & 0.0 & $<0.3$ & & $<0.24$ & & 3.2 & $<0.3$ \\
\hline $10-27$ & 2.0 & 126 & 0.59 & -2.7 & & 2 & $<0.28$ & 17 & & \\
\hline $12-22$ & 1.9 & 136 & 0.80 & 3.5 & & 3 & $<0.28$ & 13 & & \\
\hline $95-03-16$ & 1.9 & 118 & 0.92 & 3.0 & $<0.3$ & 4 & $<0.27$ & 25 & 2.8 & $<0.3$ \\
\hline 08-16 & 1.5 & 106 & 1.69 & -1.9 & & 2 & $<0.25$ & 12 & 2.4 & $<0.3$ \\
\hline $\begin{array}{r}\text { normal } \\
\text { range }\end{array}$ & $\begin{array}{r}1.4 \\
2.3\end{array}$ & $\begin{array}{l}60- \\
151\end{array}$ & $\begin{array}{r}0.41- \\
4.10\end{array}$ & $<15$ & $<0.3$ & $<35$ & $<0.30$ & $<30$ & $\leqq 0.3$ & $\leqq 0.3$ \\
\hline
\end{tabular}

$\mathrm{TSBAb}$ (thyroid-stimulation blocking antibodies) activity was not detected throughout the investigation period. \#: bovine TSH equivalent. TBII, TSH-binding inhibitor immunoglobulins; TSAb, thyroid-stimulating antibodies; $\mathrm{Tg}$, thyroglobulin; CRP, C-reactive protein; ESR, erythrocyte sedimentation rate; TgAb, anti-thyroglobulin antibodies; TPOAb, anti-thyroid peroxidase antibodies; RAIU, radioactive iodine uptake.

1) multinucleated giant cells were not demonstrated in the specimen obtained in the aspiration biopsy and 2) she does not have HLA-B35 [7-9] or HLAB67 [9].

Ultrasonic examination often provides useful information about the destructive change in the thyroid gland [10-14], although no ultrasonic findings have been reported in cases of Graves' disease associated with painful thyroiditis [1-5]. In the present study, an ultrasonogram obtained in January 1994 (Fig. 1) did not show that the whole thyroid gland was hypoechoic, indicating that the pain and tenderness in the thyroid gland were not the results of acute exacerbation of underlying chronic thyroiditis [14]. Ultrasonogram results will therefore help us to understand the clinical course in the cases of Graves' disease associated with destructive thyroiditis $[10,11]$.

The third RAIU test was done in May 1994 after the resolution of inflammation of the thyroid gland. As shown in Table 1, the third RAIU was higher than the first and second RAIUs and above the normal range although the patient's serum levels of thyroid hormone and TSAb were decreased. These results indicate that 1 ) the high serum levels of thyroid hormones in the early phase were due to Graves' disease itself and the destruction of the thyroid gland induced by thyroiditis and 2) the low first and second RAIU results were due in part to the presence of thyroiditis. In addition, the first and second scintigrams and ultrasonograms revealed that the inflammatory process did not involve the entire thyroid gland. These findings and the presence of TSAb in the patient's serum may explain why the first and second RAIUs were not below the normal range.

Fukata et al. [2] reported on four patients with Graves' disease who became hypothyroid after the onset of pain in the thyroid gland. The pain developed in two untreated patients whose RAIUs were $47.7 \%$ and $60.0 \%$ and in the two other patients during treatment with methimazole. Fine needle aspiration biopsies revealed the presence of many lymphocytes in the specimens, similar to the cases 
for the present patient, in the cases of the two untreated patients and one of the cases of the two treated patients. A needle biopsy showed the presence of chronic thyroiditis in the other treated patient. These four patients had high serum titers of antithyroid antibodies (TgAb and antimicrosomal antibodies) as measured by the hemagglutination method. Fukuta et al. [2] speculated that the patients had both Graves' disease and Hashimoto's thyroiditis and that the clinical features were dependent on the balance between the severities of these two diseases. They considered that the clinical features of Hashimoto's thyroiditis became prominent upon the resolution of the pain and so the patients became hypothyroid. Shigemasa et al. [4] suggesetd that high serum levels of anti-microsomal antibodies might be involved in the development of hypothyroidism in such patients after the onset of the pain.

Thyroid function became normal upon the resolution of the painful thyroiditis in our case. Mitani et al. [1] reported on a similar case of a patient with Graves' disease associated with subacute thyroiditis whose ${ }^{99 \mathrm{~m} T c-t h y r o i d a l ~ u p t a k e}$ rate was increased. They detected no antithyroid antibodies in the serum of this patient by the hemagglutination method. Previously we [3] reported on a Graves' disease patient whose serum thyroid hormone levels were decreased but remained high after the resolution of the pain and who did not have antithyroid antibodies in his serum as determined by the particle agglutination method. It is therefore suggested that hypothyroidism may not develop in Graves' disease patients upon the resolution of the pain when they have low serum titers of antithyroid antibodies or lack these antibodies.

Various findings have been reported concerning the changes in the serum levels of TBII and TSA $b$ in these patients. Fukuta et al. [2] reported that the serum TSAb level decreased in three out of four patients but the changes in the serum TBII level were variable (increased in two and decreased in two). They also demonstrated the appearance of $\mathrm{TSBAb}$ in the serum in one patient. Mitani et al. [1] also reported that serum TSAb and TBII levels decreased in one patient. In contrast, we previously observed that the serum TBII levels were similar both before and after the painful thyroiditis in one patient [3]. In the present study, the serum levels of antithyroid antibodies, TBII and TSAb increased transiently and then decreased, and finally all of these antibodies except $\mathrm{TgAb}$ were no longer detected, as shown in Table 1. Our present findings suggest that the mechanism(s) of the production and/or degradation of TBII and TSAb was similar to that for antithyroid antibodies during and after the painful attack in the present patient.

TSH receptor antibodies including TBII, TSAb and TSBAb are detected in the serum of some patients with destructive thyroiditis such as subacute $[12,13,15]$ and silent thyroiditis $[16,17]$; so, we cannot rule out the possibility that the thyroiditis may have acted as a trigger for the production of TBII and TSAb and induced the transient Graves' disease in the present patient [12].

Finally, the present findings indicate that remission may occur in some patients with Graves' disease after the painful thyroiditis is resolved, and therefore careful follow-up is necessary for Graves' disease patients after the development of painful thyroiditis. In addition, the changes in ultrasonogram, the percentage of RAIU and 123I scintigram could help us to understand the clinical course in these patients.

\section{Acknowledgment}

We thank the Special Reference Laboratories (SRL) for TSAb and TSBAb assays with FRTL-5 cells.

\section{References}

1. Mitani $Y$, Shigemasa C, Kouchi T, Taniguchi S, Ueta Y, Yoshida A, Mashiba H (1992) Detection of thyroid-stimulating antibody in patients with inflammatory thyrotoxicosis. Horm Res 37: 196201.

2. Fukata S, Matsuzuka F, Hara T, Mukuta T, Kuma
K, Sugawara (1993) Rapidly progressive thyroid failure in Graves' disease after painful attack in the thyroid gland. Arch Intern Med 153: 2157-2161.

3. Nakamura S, Yokoyama M, Kosaka J, Watanabe H, Shima H, Ido T (1989) Two cases of Graves' disease with subacute thyroiditis. In: Lee M, Koh C-S, 
Eastman CJ, Nagataki S (eds) Progress in Thyroidology 1989. Korea Medical Publishing Company, Seoul, 395-398.

4. Shigemasa C, Mitani Y, Taniguchi S, Adachi T, Ueta Y, Urabe K, Miyazaki S, Tanaka T, Yoshida A, Mashiba H (1990) Three patients who spontaneously developed persistent hypothyroidism during or following treatment with antithyroid drugs for Graves' hyperthyroidism. Arch Intern Med 150: 1105-1109.

5. Shigemasa S, Shirota K, Urabe K, Kouchi T, Mitani Y, Ueta Y, Yoshida A, Mashiba H (1991) Onset of subacute aggravation of chronic thyroiditis followed immediately by transient hypothyroidism during antithyroid drug therapy for Graves' hyperthyroidism. Horm Res 35: 208-212.

6. Watanabe $\mathrm{Y}$, Yonezawa M, Hikichi K, Amino N, Tamaoki H, Miyai K (1987) Measurement of thyroid stimulating antibodies and $\mathrm{TSH}$ stimulating inhibitor antibodies using cultured porcine thyroid cells. Horumon to Rinshou (Clin Endocrinol (Tokyo)) 35: 637-642 (In Japanese).

7. Ishihara $\mathrm{T}$, Mori $\mathrm{T}$, Waseda $\mathrm{N}$, Ikekubo $\mathrm{K}$, Kurahachi H, Imura H (1988) Histocompatibility lymphocytic antigen (HLA) typing in patients with acute exacerbation of Hashimoto's thyroiditis. Endocrinol Japon 35: 231-236.

8. Tamai H, Goto H, Uno H, Sasazuki T, Kuma K, Hayashi Y, Matsubayashi S (1984) HLA in Japanese patients with subacute (De Quervain's) thyroiditis. Tissue Antigen 24: 58-59.

9. Ohsako N, Tamai H, Sudo T, Mukuta T, Tanaka H, Kuma K, Kimura A, Sasazuki T (1995) Clinical characteristics of subacute thyroiditis classified according to human leukocyte antigen typing. $J$ Clin Endocrinol Metab 80: 3653-3656.

10. Nakamura S, Saio Y, Shimada T, Matsui I (1995) Transient hypothyroidism in a case of untreated
Graves' disease. Endocr J 42: 77-81.

11. Nakamura S, Saio $Y$, Ishimori M, Suzuki E, Shima H, Matsui I (1996) A Case of Graves' disease in which hypothyroidism first developed, followed by hyperthyroidism, and finally hypothyroidism recurred: A four-year follow up. Folia Endocrinol Japon 72: 669-676 (In Japanese, abstract in English).

12. Nakamura S, Hattori J, Ishiyama-Takuno M, Shima H, Matsui I, Sakata S (1992) Non-suppressed thyroidal radioactive iodine uptake (RAIU) in thyrotoxic phase in a case of subacute thyroiditis with thyroid-stimulating antibodies (TSAb). Endocrinol Japon 39: 469-476.

13. Nakamura S, Saio Y, Suzuki E (1996) Subacute thyroiditis with thyroid-stimulation blocking antibodies: A case report. Endocr J 43: 185-189.

14. Shigemasa $C$, Ueta $Y$, Mitani $Y$, Taniguchi $S$, Urabe K, Tanaka T, Yoshida A, Mashiba H (1990) Chronic thyroiditis with painful tender thyroid enlargement and transient thyrotoxicosis. J Clin Endocrinol Metab 70: 385-390.

15. Tamai H, Nozaki T, Mukuta T, Morita $T$, Matsubayashi S, Kuma K, Kumagai LF, Nagataki S (1991) The incidence of thyroid stimulating blocking antibodies during the hypothyroid phase in patients with subacute thyroiditis. J Clin Endocrinol Metab 73: 245-250.

16. Morita T, Tamai H, Oshima A, Mukuta T, Fukata S, Kuma K, Kumagai LF, Nagataki S (1990) The occurrence of thyrotropin binding-inhibiting immunoglobulins and thyroid-stimulating antibodies in patients with silent thyroiditis. J Clin Endocrinol Metab 71: 1051-1055.

17. Nakamura S, Sugimoto M, Kosaka J, Watanabe $H$, Shima H, Kawahira S (1990) Silent thyroiditis with thyroid-stimulation-blocking antibodies (TSBAb). Jpn J Med 29: 623-627. 